\title{
Возможности 3D-технологий в создании виртуальных реконструкций объектов историко-культурного наследия (на примере виртуальной трехмерной реконструкции интерьера столовой в доме П.С. Строганова)
}

\author{
Г.П. Жиркова, Д.О. Мартынова, А.А. Смолин \\ Университет ИТМО, Россия \\ reponse@mail.ru, domartynova@itmo.ru, smolineitmo.ru
}

\begin{abstract}
Аннотация. Настоящая статья посвящена описанию и анализу результатов междисциплинарного проекта, разработанного и реализованного Центром социальных и гуманитарных знаний и Центром юзабилити и смешанной реальности Университета ИТМО. Этот проект направлен на сохранение, частичную музеефикацию и подготовку к научной реставрации особняка П.С. Строганова. В рамках исследования был проведен тест создания трехмерного объекта средствами фотограмметрии в программе Agisoft Metashape, а также тестовый экспорт и рендер в 3Ds Max. При подготовке к построению сцены все уникальные элементы интерьера были отсняты на фотокамеру Nikon D3200. Для визуализации сцены использовался редактор Unity, программное обеспечение которого подходит для настройки освещения с цветофильтрами. Опираясь на полученные визуальные материалы и проведенные исследования, авторы показывают значение цифровых технологий для реконструкции памятников историко-культурного наследия, демонстрируя дальнейшие возможности для их использования. Авторы приходят к выводу, что репрезентация этих объектов в цифровом поле может стать драйвером диалога между прошлым и современным, что приведет к поиску новых механизмов взаимодействия в городском пространстве.
\end{abstract}

Ключевые слова: виртуальная реконструкция, междисциплинарные исследования, дом П.С. Строганова, культурное наследие, фотограмметрия.

В последние десятилетия цифровые гуманитарные науки (Digital Humanities) активно завоевывают место в гуманитарных междисциплинарных исследованиях. Особенно успешно включились в процесс использования компьютерных технологий для решения научных задач филология и история. Если изначально историки использовали измерительные технологии, то в дальнейшем все более актуальным становится обращение к виртуальной реконструкции объектов архитектурного и художественного наследия, пространственной репрезентации и созданию ГИСприложений в историко-культурных исследованиях. Это связано с быстрым развитием технологий компьютерных визуализаций, расширением технических возможностей и большей доступностью технологий фотограмметрии.

Современные технологии 3D-моделирования позволяют осуществлять реконструкцию и визуализацию объектов историко-культурного наследия с использованием гиперреалистичной 
аутентичной визуализации, интерактивности и анимации, а также проводить цифровую реставрацию объектов. Этот подход особенно востребован в последние годы при создании новых музеев и экспозиций, реставрации памятников истории и культуры. Его реализация, как правило, проходит в формате междисциплинарных проектов.

Интересным примером таких разработок является междисциплинарный проект, разработанный и реализованный Центром социальных и гуманитарных знаний и Центром юзабилити и смешанной реальности Университета ИТМО, направленный на сохранение, частичную музеефикацию и подготовку к научной реставрации особняка П.С. Строганова (ул. Чайковского, 11/2, ныне корпус факультета технологического менеджмента и инноваций Университета ИТМО). В рамках этого проекта создана виртуальная трехмерная реконструкция интерьера столовой в доме П.С. Строганова.

Особняк графа Павла Сергеевича Строганова и его супруги Анны Дмитриевны (в девичестве Бутурлиной) был построен на Сергиевской улице (ныне ул. Чайковского) придворным зодчим Ипполитом Антоновичем Монигетти в 1857-1859 годах [1, с. 54-56]. В 1878-1882 годах архитектор Максимилиан Егорович Месмахер надстроил левую часть крыла до двух этажей с устройством на втором этаже домовой церкви Спаса Нерукотворного, освященной в 1882 году [2, с. 23].

Дом был построен в стиле эклектики и, несмотря на поздние надстройки, неплохо сохранился. Он является памятником историко-культурного наследия регионального значения и менее известен, чем дворец Строгановых на углу Невского проспекта и набережной реки Мойки. Между тем во второй половине XIX века это был один из примечательных особняков СанктПетербурга. Восхищение вызывали не только интерьеры дома. Его хозяин, страстный коллекционер, превратил своё жилище в настоящий музей. В художественном отделе журнала «Пчела» за 1875 год (№ 1-4) известный русский писатель Дмитрий Васильевич Григорович подробно описал дом и коллекцию графа П.С. Строганова [3]. Писатель, как отмечал С.О. Кузнецов, вероятно, создал и своего рода «миф дома» [4, с. 35]. Григорович писал: «По мере того, как собрание росло, и предметы умножались, приходила мысль об устройстве дома для их помещения, дом строился ввиду расположения в нём купленных вещей,... каждой вещи предназначался заранее уютный угол, каждая стена и окно выводились с целью выгодной установки и освещения» [3, с. 9]. Далее идет скрупулезное описание предметов коллекции и их месторасположения.

О богатстве и изысканности интерьеров дома Павла Сергеевича Строганова можно судить и на основании сохранившихся акварелей художника Жюля Мейблюма, ученика петербургской Академии художеств (собрание Государственного Эрмитажа). Тринадцать акварелей, собранных в альбом, детально воспроизводят интерьеры. Акварели были выполнены в 1863-1865 годах. В это же время интерьеры особняка запечатлел «первый светописец Петербурга» Иван (Джованни) Карлович Бианки [5, с. 721]. Стоит отметить, что композиционно фотоработы Бианки схожи с акварелями Мейблюма.

Богатейший материал по истории дома и коллекции П.С. Строганова был представлен на выставке «Забытый русский меценат», проходившей в Государственном Эрмитаже с 7 июля по 19 октября 2019 года.

Таким образом, визуальные и литературные материалы дают довольно полную картину архитектуры дома, его интерьеров и коллекции П.С. Строганова. По результатам исследовательской работы сотрудников Центра социальных и гуманитарных знаний Университета ИТМО создается база данных для информационного Интернет-ресурса, виртуальной трехмерной реконструкции интерьеров, а также для построения пространственных репрезентаций исторической информации на интерактивных картах. Материал, собранный сотрудниками центра, несомненно, будет востребован для научной реставрации объекта, а также реализации идеи создания музея, который бы объединил прошлое, настоящее и будущее: память о П.С. Строганове, его доме и коллекциях и инновационные технологии, которые разрабатываются в Университете ИТМО.

База данных была использована и при реализации проекта виртуальной трехмерной реконструкции интерьера столовой в доме П.С. Строганова в рамках конкурса студенческих

Культура и технологии, Том 6, № 1 
Возможности 3D-технологий в создании виртуальных реконструкций объектов историко-культурного наследия (на примере виртуальной трехмерной реконструкции

инициатив «ITMO.Future» Университета ИТМО. Дополнительно был проведен сбор визуальных и источниковедческих материалов, анализ музейных коллекций с целью выявления предметов, связанных с домом П.С. Строганова. Под руководством менторов проекта Жирковой Г.П. и Смолина А. . и информационной поддержке Мартыновой Д.О., студенты магистерских программ Воробьев П.В., Иванова Ю.С. и Кузенкова Е.В. выполнили проект и разместили полученные материалы на видеохостинге Youtube [6].

Для создания модели также были выполнены работы по снятию базовых габаритов помещения, оценке внешнего состояния и освещения объекта, выполнена фотограмметрия. С помощью собранных данных был проведен тест создания трехмерного объекта средствами фотограмметрии в программе Agisoft Metashape, а также тестовый экспорт и рендера в 3Ds Max.

При подготовке к построению сцены все уникальные элементы интерьера отсняты на фотокамеру Nikon D3200. Для уменьшения перспективных искажений было выбрано фокусное расстояние в 50 мм, в дальнейшем оно оставалось неизменным на протяжении всей съемки. Каждый элемент был отснят дважды с разного удаления и ракурсов. Это дало возможность построить верную геометрию каждого элемента: за счет контраста света и тени на фотографиях программа смогла определить объем и глубину полученных элементов. Далее из полученных результатов была собрана сцена.

Для визуализации сцены использовался редактор Unity, программное обеспечение которого подходит для настройки освещения с цветофильтрами. Такой подход позволяет добиться большего сходства с изображениями столовой и передать атмосферу ушедшего века. Также была создана камера для захвата равноширинных изображений в разрешении HD с частотой 60 кадров в секунду. Именно на базе таких изображений выстраивается панорамное видео для загрузки в сервисы распространения видео, например, Youtube.

Созданный продукт позволяет представить деятельность по сохранению историкокультурного наследия как инновационную, и придает сохраняемому объекту современную функциональность: образовательную, просветительскую, туристическую и иную.

Модель междисциплинарного взаимодействия в рамках подобного проекта также представляет определенный алгоритм работы с памятниками историко-культурного наследия. Это особенно важно для Санкт-Петербурга, в котором сосредоточено около $10 \%$ объектов историкокультурного наследия Российской Федерации. Когда говорят о культурном наследии города, прежде всего, подразумевают всемирно известные памятники (федерального подчинения), забывая, что уникальность историко-культурной среды определяет и широчайший масштаб исторической застройки, в которой в настоящее время ещё сохранились многочисленные памятники истории и культуры регионального подчинения. Многие из этих памятников находятся в плохой сохранности и могут быть утрачены уже в ближайшее время. Репрезентация этих объектов в цифровом поле станет драйвером диалога между прошлым и современным, что приведет к поиску новых механизмов взаимодействия в городском пространстве. Итогом такого сотрудничества могут стать проекты, которые будут работать одновременно и на сохранение объекта историко-культурного наследия и на придание ему новой функциональности, отвечающей современной потребности города.

\section{Литература}

[1] Листов В. И. Ипполит Монигетти. Л.: Стройиздат, 1976.

[2] Тыжненко Т. Е. Максимилиан Месмахер. Л.: Лениздат, 1984.

[3] Григорович Д.В. Дом графа П.С. Строганова// Пчела: Русская иллюстрация, журнал искусства и литературы, политики и общественной жизни. 1875. № 1-4 С.8-12, 26-28, 39-41, 49-52.

[4] Забытый русский меценат. Собрание графа Павла Сергеевича Строганова // Каталог выставки. СПб.: Изд-во Государственного Эрмитажа 2019.

[5] Семенова Ю.Г., Терентьева И.О. «Античность» в кабинете графа С.Г. Строганова: пример реконструкции по фотографии И. Бианки 1865 года // Актуальные проблемы теории и истории искусства. Вып.8. 2018. С. 715-833.

International Culture \& Technology Studies, Vol. 6, No. 1 
[6] ITMO.FUTURE 2020 (2020). Режим доступа: https://youtu.be/zA693x2UdpA (дата обращения: 18.03.2021)

\title{
Possibilities of 3D technologies in the creation of virtual reconstructions of objects of historical and cultural heritage (on the example of a virtual three-dimensional reconstruction of the dining room interior in the house of P.S. Stroganov)
}

\author{
G.P. Zhirkova, D.O. Martynova, A.A. Smolin
}

ITMO University, Russia

\begin{abstract}
This article is devoted to the description and analysis of the results of an interdisciplinary project developed and implemented by the Center for Social and Humanitarian Knowledge and the Center for Usability and Mixed Reality at ITMO University. This project is aimed at preserving, partial museumification and preparation for the scientific restoration of the Stroganov mansion. As part of the study, a test of creating a three-dimensional object by means of photogrammetry in the Agisoft Metashape program was carried out, as well as a test export and rendering in 3Ds Max. In preparation for the construction of the scene, all the unique elements of the interior were captured on a Nikon D3200 camera. To render the scene, the Unity editor was used, the software of which is suitable for setting up lighting with color filters. Based on the visual materials obtained and the research carried out, the authors show the importance of digital technologies for the reconstruction of monuments of historical and cultural heritage, demonstrating further possibilities for their use. The authors come to the conclusion that the representation of these objects in the digital field can become a driver of the dialogue between the past and the present, which will lead to the search for new mechanisms of interaction in the urban space.
\end{abstract}

Keywords: virtual reconstruction, interdisciplinary research, P. S. Stroganov's house, cultural heritage, photogrammetry

\section{References}

[1] Listov, V. I. (1976). Ippolito Monighetti. Leningrad. Strojizdat Publ. 1976.

[2] Tyzhnenko, T. E. (1984). Maximilian von Messmacher. Leningrad. Lenizdat Publ. 1984.

[3] Grigorovich, D.V. (1875). Dom grafa P.S. Stroganova [The House of Count P. S. Stroganov]. Pchela: Russkaya illyustraciya, zhurnal iskusstva i literatury, politiki i obshchestvennoj zhizni - [The Bee: Russian illustration, magazine of art and literature, politics and public life]. No. 1-4. 8-52.

[4] Zabytyj russkij mecenat. Sobranie grafa Pavla Sergeevicha Stroganova // Katalog vystavki. SPb.: Izd-vo Gosudarstvennogo Ermitazha 2019.

[5] Semenova Yu. G., Terent'eva I.O. (2018). «Antichnost'» v kabinete grafa S.G. Stroganova: primer rekonstrukcii po fotografii I.Bianki 1865 goda ["Classical Antiquity" in Sergei G. Stroganoff 's Grand Cabinet: A Case of Reconstruction after the Photo by Giovanni Bianchi (1865)]. Aktual'nye problemy teorii i istorii iskusstva [Actual Problems of Theory and History of Art]. No. 8. 715-833.

[6] ITMO.FUTURE 2020 (2020). Available at: https://youtu.be/zA693x2UdpA (accessed date: 18.03.2021). 